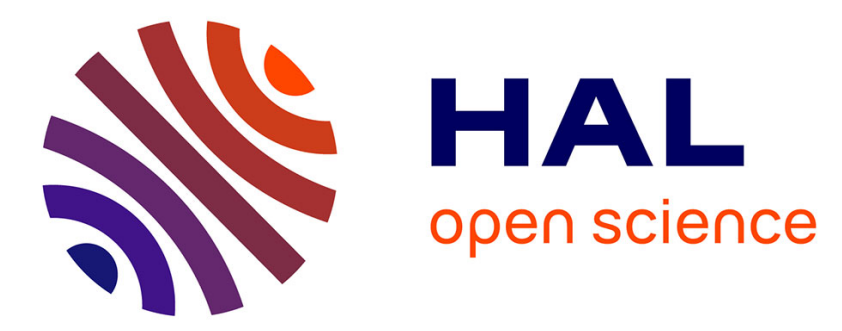

\title{
Characterization of CdTe with photoelectronic techniques
}

\author{
A.M. Mancini, C. Manfredotti, C. de Blasi, G. Micocci, A. Tepore
}

\section{To cite this version:}

A.M. Mancini, C. Manfredotti, C. de Blasi, G. Micocci, A. Tepore. Characterization of CdTe with photoelectronic techniques. Revue de Physique Appliquée, 1977, 12 (2), pp.255-261. 10.1051/rphysap:01977001202025500 . jpa-00244154

\section{HAL Id: jpa-00244154 https://hal.science/jpa-00244154}

Submitted on 1 Jan 1977

HAL is a multi-disciplinary open access archive for the deposit and dissemination of scientific research documents, whether they are published or not. The documents may come from teaching and research institutions in France or abroad, or from public or private research centers.
L'archive ouverte pluridisciplinaire HAL, est destinée au dépôt et à la diffusion de documents scientifiques de niveau recherche, publiés ou non, émanant des établissements d'enseignement et de recherche français ou étrangers, des laboratoires publics ou privés. 


\title{
CHARACTERIZATION OF CdTe WITH PHOTOELECTRONIC TECHNIQUES
}

\author{
A. M. MANCINI and C. MANFREDOTTI \\ Istituto di Fisica, Bari and Sezione I. N. F. N., Bari, Italy \\ and \\ C. DE BLASI, G. MICOCCI and A. TEPORE \\ Istituto di Fisica, Lecce, Italy
}

\begin{abstract}
Résumé. - Des mesures de courants thermostimulés ou limités par charge d'espace ont été employées pour caractériser des cristaux de tellurure de cadmium préparés soit par la méthode de Bridgman (avec différents niveaux de dopage à l'In) soit par le procédé THM sous solvant tellure (avec dopage au $\mathrm{Cl}$ ). Les pièges suivants ont été identifiés : pour les trous, des niveaux localisés à $0,07,0,14,0,25,0,36 \mathrm{eV}$ de la bande de valence, pour les électrons à $0,05,0,34,052 \mathrm{et} 0,62 \mathrm{eV}$ de la bande de conduction. A partir des mesures de résistivité en fonction de la température il a été possible de déterminer les niveaux donneurs et accepteurs, respectivement. L'analyse des courbes de courants thermostimulés et de charge d'espace a été effectuée de plusieurs façons, afin de déterminer les conditions optimales d'analyse. Finalement, les mérites respectifs de ces deux procédés de caractérisation seront discutés dans le cas où elles sont mises en œuvre sur CdTe.

Abstract. - Thermally stimulated current (TSC) and space-charge limited current (SCLC) measurements have been performed in CdTe grown by Bridgman method with various In dopings and grown from Te-rich solution with $\mathrm{Cl}$ doping. Hole traps have been evidenced at $0.07,0.14$, 0.25 and $0.36 \mathrm{eV}$ from valence band, while electron traps are at $0.05,0.34,0.52$ and $0.62 \mathrm{eV}$ from conduction band. Measurements of activation energies of resistivity vs temperature curves indicate which of these should correspond to donors or acceptors centers. Various methods of analysis were used both for TSC and for SCLC results, in order to determine the more suitable ones. Finally TSC and SCLC are compared and discussed as methods for CdTe characterization.
\end{abstract}

1. Introduction. - The development of CdTe as room temperature $\gamma$-ray detector poses severe problems concerning its characterization and, particularly, the determination of shallow and deep traps, which contribute to deteriorate its detector performance. To this purpose, techniques concerning transient currents, obtained either by nuclear $[1,2]$ or optical [3] excitation have been used and, recently, TSC techniques $[4,5]$ have been applied, in order to correlate somehow the levels spectroscopy with the detector characteristics. Both techniques suffer some disadvantage since, for instance, TSC is more suitable for shallow levels, while deep levels are certainly those playing a fundamental role in limiting the trapping time. Time-of-flight methods, either in space-charge limited or in space-charge free configurations are cumbersome, can be used only for a good $\mathrm{CdTe}$ and give informations on traps only in a relatively complicated way.

The aim of this paper is to demonstrate that, by using simultaneously TSC and SCLC methods one can obtain a complete spectroscopy of the trapping levels for the sample investigated in a simple way, both from an experimental and analytical point of view. In particular, the advantages of using the steady-state SCLC method for detecting deep-lying traps with relatively low densities are discussed.

2. Experimental procedure. - CdTe crystals used for the present investigation were grown by the Bridgman technique, by adding quantities ranging from $1 \mathrm{ppm}$ to $20 \mathrm{ppm}$ of In to the starting material. Some crystals, obtained from Hughes Res. Lab., were grown by the same method. All these crystals turned to be n-type, with resistivities ranging from $10^{5} \Omega \mathrm{cm}$ to $10^{10} \Omega \mathrm{cm}$. Other samples, grown from Te-rich solution and $\mathrm{Cl}$-doped (400 ppm of $\mathrm{CdCl}_{2}$ added to the starting charge) were p-type, with resistivities of the order of $10^{7} \Omega \mathrm{cm}$.

For TSC measurements, the samples were equipped with semitransparent $100 \AA$ thick Au contacts obtained by vacuum evaporation ( $p \sim 10^{-5}$ torr). The samples were then mounted in a $\mathrm{N}_{2}$ cryostat together with a $\mathrm{Pt}$ resistance thermometer. Constant rates of about $2 \mathrm{deg} / \mathrm{s}$ were obtained between $77 \mathrm{~K}$ and $R T$. Traps were filled by illuminating the samples at the lowest temperature with filtered (average $\lambda=0.35 \mu$ ) highly absorbed interband light. It was then possible, by changing the 
voltage polarity, to select between electron and hole trapping centers.

For SCLC measurements, alloyed Au contacts, obtained by heat-treatment of thick evaporated contacts, were used. Also In or Al contacts were sometimes used, with no appreciable difference in measured I-V characteristics. Sample thickness ranged between $200 \mu$ and $1000 \mu$, with a contact surface area of about $10 \mathrm{~mm}^{2}$.

Some samples were characterized by means of $\alpha$-particles : for solution grown samples, $\mu \tau^{+}$products of $8 \times 10^{-6} \mathrm{~cm}^{2} \mathrm{~V}^{-1}$ for holes and of $4 \times 10^{-6} \mathrm{~cm}^{2} \mathrm{~V}^{-1}$ for electrons were obtained. Bridgman grown samples had a maximum $\mu \tau^{+}=4 \times 10^{-4} \mathrm{~cm}^{2} \mathrm{~V}^{-1}$ for electrons and $\mu \tau^{+} \simeq 10^{-5} \mathrm{~cm}^{2} \mathrm{~V}^{-1}$ for holes.

3. Results. - 3.1 TSC MEASUREMENTS. - A typical TSC curve obtained for hole trapping is shown in figure 1 , where a unique peak at $T_{\mathrm{m}}=216 \mathrm{~K}$ is clearly

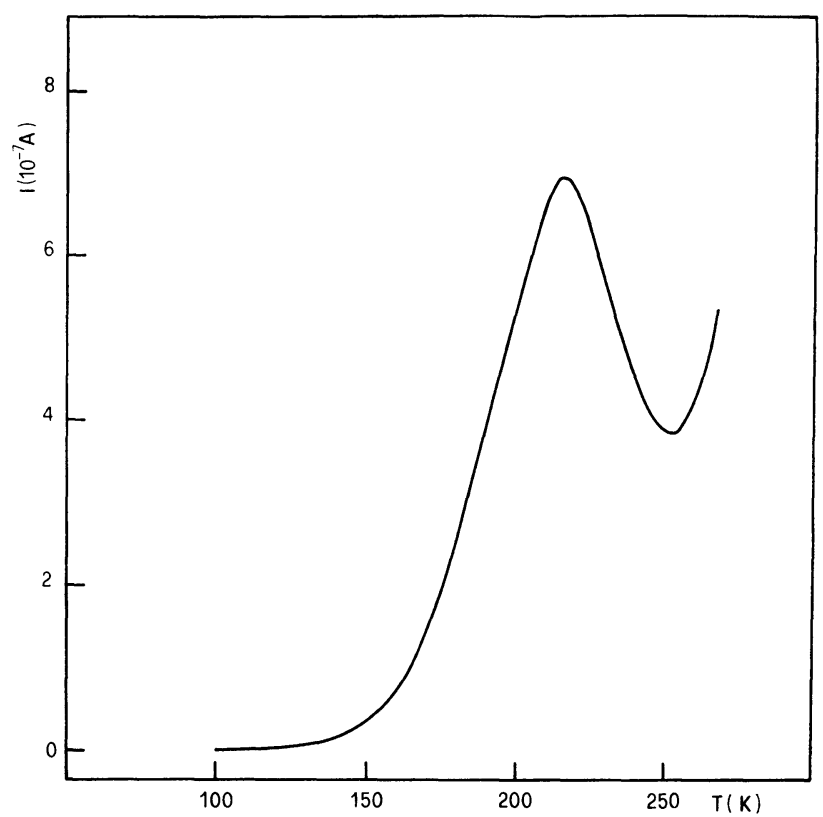

FIG. 1. - Typical TSC curve obtained for an In-doped CdTe sample in the case of hole trapping (applied bias $50 \mathrm{~V}$ ). A unique peak at $T_{\mathrm{m}}=216 \mathrm{~K}$ is clearly visible. The rising part at extreme right is due to dark current.

apparent. In such cases, the analysis can be performed by the initial rise method, as proposed by Garlick and Gibson [6], which states that in the rising part of the TSC curve the current is proportional to $\exp \left(-E_{\mathrm{T}} / k T\right)$. Therefore, the plot of the logarithm of the current as a function of $1 / k T$, as shown in figure 2, gives directly a straight line of slope $E_{\mathrm{T}}$ (the progressive shifting from linear behaviour at high currents is likely due to the overcoming of the critical temperature $T_{\mathrm{c}}$ [7], above which the Garlick-Gibson approximations are no more valid). The advantage of this method lies essentially in the fact that it is independent of recombination kinetics.

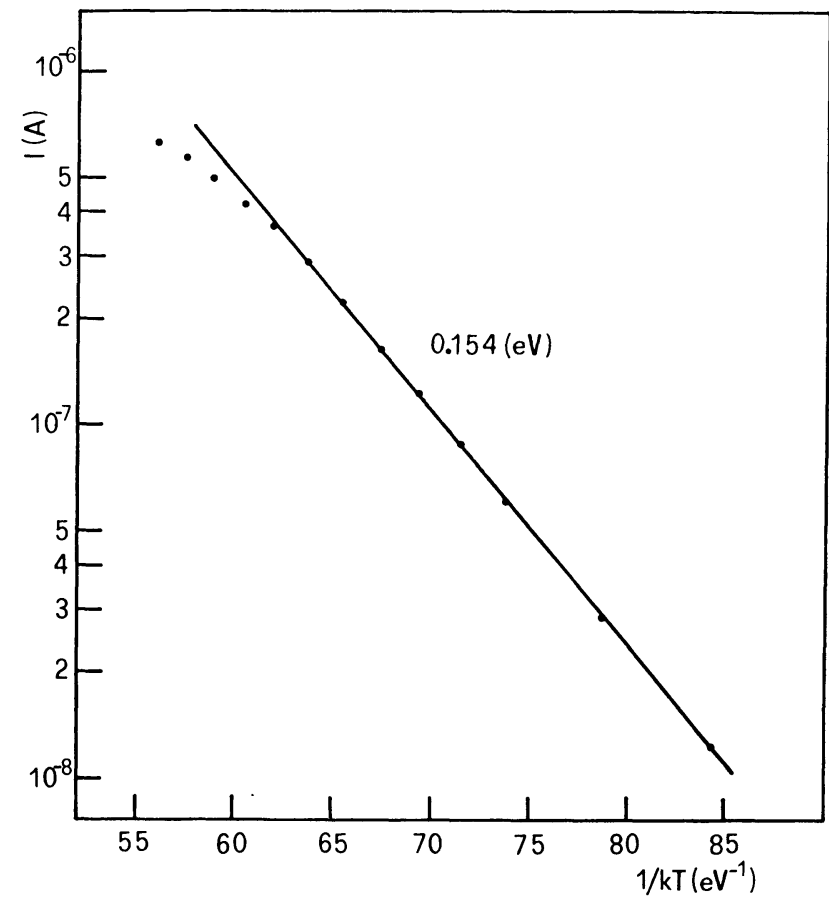

Fig. 2. - Analysis with the Garlick-Gibson method of the rising side of figure 1 . The slope indicates an energy of $0.154 \mathrm{eV}$ (from valence band).

However, sometimes TSC curves behave in a more complicated way, as shown in figure 3 , where three peaks are clearly evident. In these cases, a particular method of reconstruction has been applied [8], which

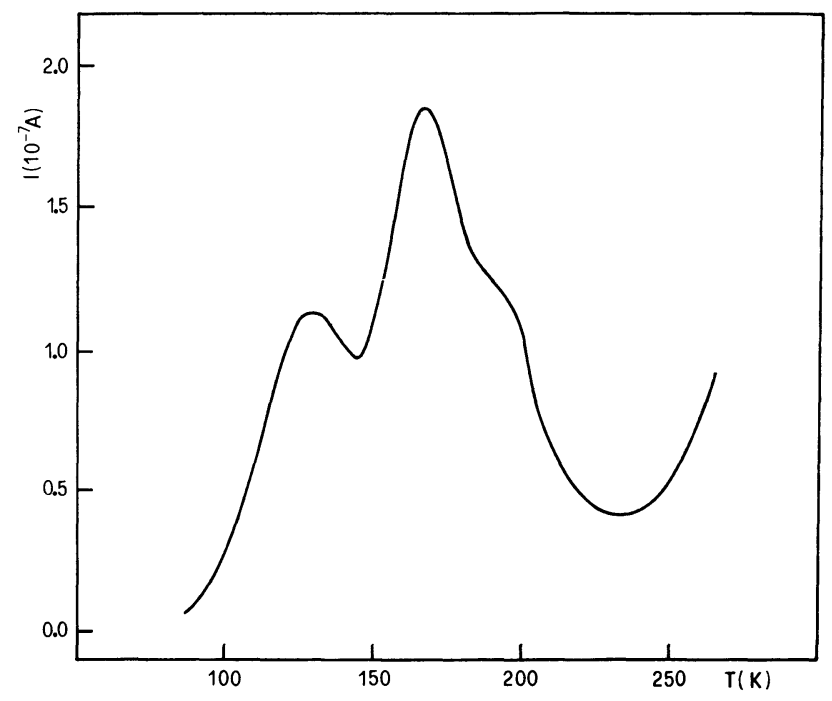

FIG. 3. - Typical TSC curve showing three peaks at $T_{\mathrm{m}}=130 \mathrm{~K}, 169 \mathrm{~K}$ and $197 \mathrm{~K}$ respectively (applied bias $30 \mathrm{~V}$, hole trapping).

works as follows. The analysis can start either from the low-temperature or from the high temperature end of the curve. In the former case, $E_{\overline{\mathrm{T}}}$ is calculated by means of the initial rise method, while a comparison with Halperin-Braner formulae as modified by Chen [9] should decide between first-order or second-order 
kinetics. Then, the total width $w$ of the first peak can be obtained, and the half-width towards fall-off of the peak $\delta=w-\tau$ (where $\tau$ is the half-width towards low-temperature side) can be evaluated. Finally, the rising portion of the next peak can be obtained by substraction, using the triangle approximation. Activation energies can then be evaluated by applying Chen's formulae [10] for general-order kinetics.

In the latter case, $E_{\mathrm{T}}$ for the last peak (where interference due to neighbouring peaks is negligible) is calculated by using Lushchik formulae as modified by Chen [9], which make use only of $\delta$. Then the total width can be calculated, $\tau=w-\delta$ can be obtained, and the analysis can be carried out in the same way as reported before. It is worthwhile to remark that this procedure has been adopted because the thermal cleaning of the peaks or the use of the decayed thermally stimulated currents [11] gave uncorrect results in the sense that the high temperature peaks kept memory of the lower temperature ones.

In the analysis, formulae due to Lushchik [12], who assumes a strong retrapping, and to Keating [13] and Grossweiner [14] (first-order kinetics) have also been used. In general, the only limitation for applying the various methods lies in the fact that some methods work on the left half-width of the peak (as for example Grossweiner's and Halperin-Braner's methods), others work on the right half-width (such the Lushchnik's methods), while not always a peak is so separated from neighbouring ones, that $\tau$ and $\delta$ can be easily calculated.

Figure 4 shows a typical example of TSC curve obtained for electron trapping, where a unique peak appears at about $140 \mathrm{~K}$. This peak, which corresponds to an electron trap at $0.05 \mathrm{eV}$ below the conduction band, practically occurs in every $\mathrm{CdTe}$ sample grown by Bridgman method.

The results obtained by TSC analysis show electron traps at $E_{\mathrm{c}}-0.05 \mathrm{eV}$ and $E_{\mathrm{c}}-0.34 \mathrm{eV}$, and hole traps at $E_{\mathrm{v}}+0.072 \mathrm{eV}, E_{\mathrm{v}}+0.144 \mathrm{eV}, E_{\mathrm{v}}+0.25 \mathrm{eV}$ and $E_{\mathrm{v}}+0.35 \mathrm{eV}$, with a good overall agreement

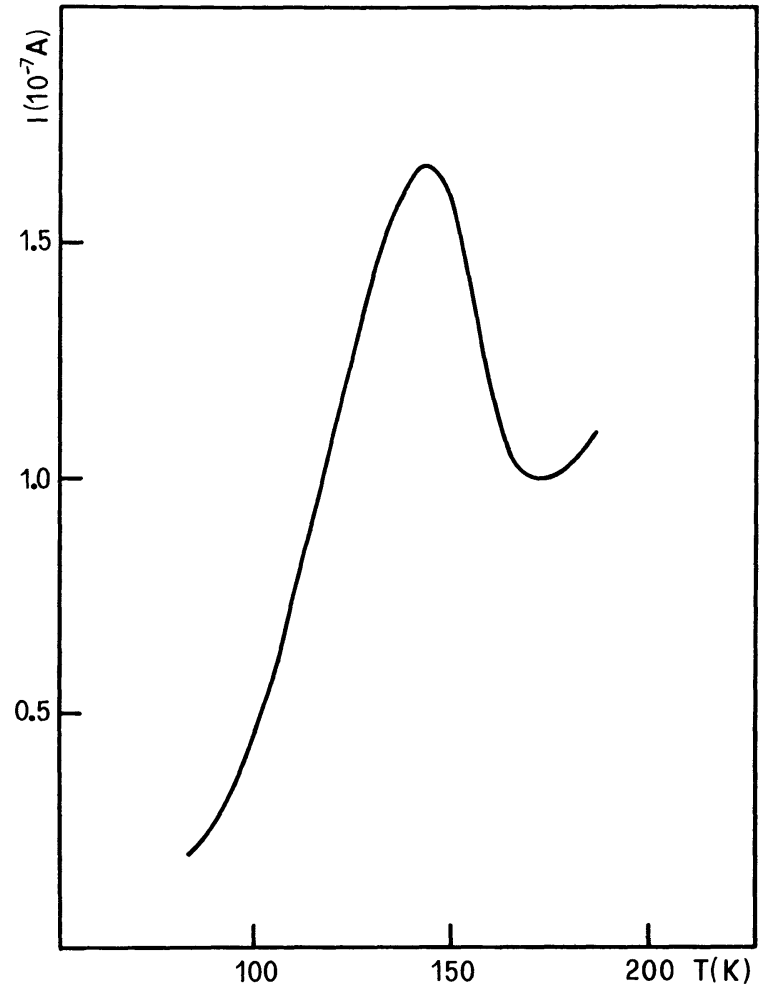

FIG. 4. - Typical TSC curve in the case of electron trapping (applied bias $55 \mathrm{~V}, T_{\mathrm{m}}=144 \mathrm{~K}$ ).

among all methods of analysis which has been used. These results will be discussed in a later seetion, together with those ones obtained with SCLC and other techniques, and with those ones quoted by other authors. As an example, here we report the results obtained for the trap at $0.144 \mathrm{eV}$ with different methods, since in this case it has been possible to use all the methods we took into consideration. The only exception is the Bube's method, which assumes a strong retrapping and which in almost all cases gives results in strong disagreement with the other methods. This comparison is shown in table I, where $E_{\tau}, E_{\delta}$ and $E_{\mathrm{w}}$

\section{TABLE I}

Comparison with the results obtained by TSC for the hole trap at $0.144 \mathrm{eV}$ as calculated by different methods and assuming first-order, second-order kinetics or strong retrapping

$\begin{array}{lccc}\begin{array}{l}\text { Method } \\ \text { Kinetics }\end{array} & \begin{array}{c}\text { Garlick } \\ {[6]}\end{array} & \begin{array}{c}\text { Halperin- } \\ \text { Braner } \\ \text { [9] }\end{array} & \begin{array}{c}\text { Lushchik } \\ \text { [9] }\end{array} \\ \text { Independent } & - & - & \\ & 0.144 \mathrm{eV} & & \\ \text { First-order } & & \\ & & E_{\tau}=0.127 \mathrm{eV} \quad E_{\delta}=0.140 \mathrm{eV} \\ \text { Second-order } & & E_{\mathrm{w}}=0.151 \mathrm{eV} & \\ & & E_{\tau}=0.147 \mathrm{eV} & \\ & & E_{\mathrm{w}}=0.195 \mathrm{eV} & \end{array}$

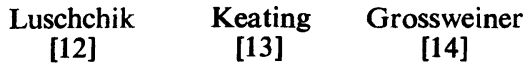


refer to trap energies calculated with formulae involving $\tau, \delta$ and $w$ respectively, and $\mu_{\mathrm{g}}=\delta / w$. Comments on this table could be the following ones : 1) Methods based on $\delta$ or $w$ could be sometimes unreliable, because determination of $\delta$ can be affected by the dark current (see Fig. 1) ; 2) The Grossweiner's and Keating's methods give quite reasonable results, even if they are out of the approximation range $\left(E_{\mathrm{T}}=8.7 k T_{\mathrm{m}}\right.$ for for Grossweiner's method, and $E_{\mathrm{T}}=7.4 k T_{\mathrm{m}}$ for Keating's method) ; 3) It is relatively impossible to decide between first and second-order kinetics in this case, as also in the other ones, except in the sense that first-order kinetics formulae seem to be in a better agreement with kinetics-independent ones, at least for the shallower peaks ; 4) Chen's method is in good agreement with Garlick-Gibson's one and, being simpler to apply and also kinetics-independent, should be clearly preferable.

Table II reports a summary of detected traps, energies and their capture cross-sections $S_{\mathrm{T}}$, as calculated

\section{TABLE II}

Average values of energies of hole and electron traps $\left(E_{\mathrm{T}}\right)$ and relative capture cross-sections $\left(S_{\mathrm{T}}\right)$

\begin{tabular}{cc}
\multicolumn{2}{c}{ Hole Traps } \\
$E_{\mathrm{T}}(\mathrm{eV})$ & $S_{\mathrm{T}}\left(\mathrm{cm}^{2}\right)$ \\
- & - \\
0.072 & $4.4 \times 10^{-24}$ \\
0.144 & $3.4 \times 10^{-23}$ \\
0.25 & $6 \times 10^{-20}$ \\
0.35 & $2.8 \times 10^{-17}$
\end{tabular}

Electron Traps

$$
\begin{array}{cc}
E_{\mathrm{T}}(\mathrm{eV}) & S_{\mathrm{T}}\left(\mathrm{cm}^{2}\right) \\
- & - \\
0.05 & 1.5 \times 10^{-25} \\
- & - \\
0.34 & 1.3 \times 10^{-18}
\end{array}
$$

with the formula due to Garlick-Gibson [7]. It is worthwhile to note that also Grossweiner's [14] and Chen's [10] formulae give practically the same results for $S_{\mathrm{T}}$.

3.2 SCLC MEASUREMENTS. - A typical SCLC characteristics obtained at RT for an In-doped CdTe sample is shown in figure 5 . One can easily observe an ohmic region, a quadratic region (where space-charge effects due to filling of traps play a role), a steeply rising region, which can be interpreted as the trapfilling limit (TFL), and which ends with a new quadratic region. By using the Lampert's model [15], which assumes a single set of discrete trapping centers, one obtains $E_{\mathrm{T}}=0.53 \mathrm{eV}$, with a density

$$
N_{\mathrm{T}}=3 \times 10^{10} \mathrm{~cm}^{-3} \text {. }
$$

Two facts are to be remarked at this point : 1) The trap density is given by the relationship

$$
N_{\mathrm{T}}=\frac{2 \varepsilon V_{\mathrm{TFL}}}{e d^{2}}
$$

where $\varepsilon$ is the static dielectric constant, $V_{\text {TFL }}$ is the voltage at which TFL region begins and $d$ is the sample thickness. It is then obvious that samples of high

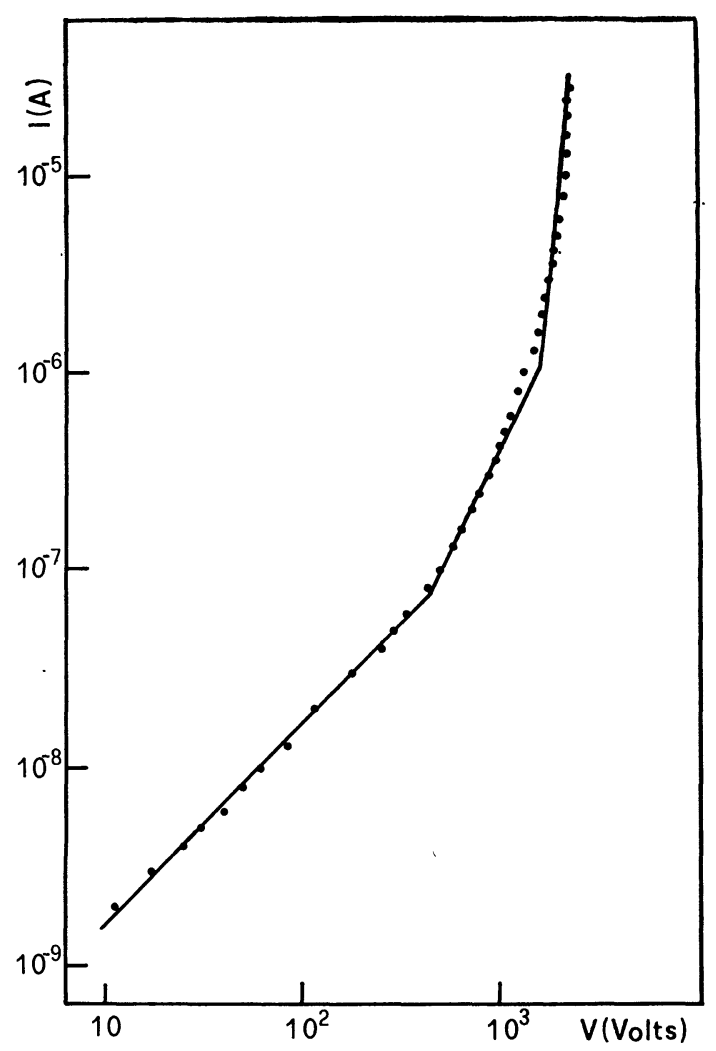

FIG. 5. - Typical I-V characteristics for an In-doped CdTe sample, showing an example of a discrete level and of a trap-free Mott-Gurney law.

purity, and therefore with a lower density of traps, give a lower $V_{\text {TFL }}$, i. e. more readily observable before other effects (e. g. Joule's heating or contact breakdown) can occur ; 2) In the case where the free carrier density $n \gg N_{\mathrm{T}}$, the sample behaves essentially like a trap-free insulator and the current density $J$ through it can be expressed by the relationship

$$
J=\frac{9}{8} \varepsilon \mu \frac{V^{2}}{d^{3}}
$$

(where $\mu$ is the drift mobility) usually referred as MottGurney law [16]. If one interprets the higher quadratic region in this way taking into account that there are no traps close in energy to $0.53 \mathrm{eV}$ level in CdTe and that the condition $n \gg N_{\mathrm{T}}$ is fulfilled, one obtains $\mu=400 \mathrm{~cm}^{2} \mathrm{~V}^{-1} \mathrm{~s}^{-1}$, which is quite reasonable for the investigated sample. Unfortunately, there were no other cases like this in the present preliminary measurements, and therefore this point can be taken as an indication of the possibilities of SCLC method.

The hypothesis of the Lampert's model can be overcome by using a new method of analysis [17] which works directly on the I-V characteristics themselves without any particular assumption concerning the nature of the trap distribution (e. g. discrete or diffuse) and by which the parameters of the trap distributions can be easily obtained. An example of such an analysis is shown in figure 6, which displays the 


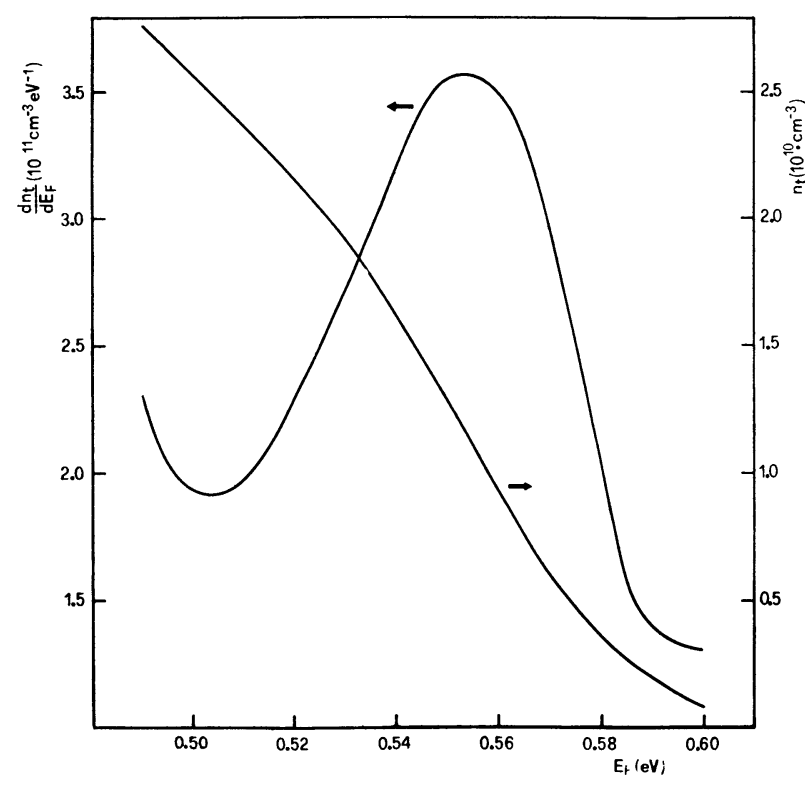

Fig. 6. - Behaviour of trapped electron density $\left(n_{t}\right)$ and of $\mathrm{d} n_{\mathrm{t}} / \mathrm{d} E_{\mathrm{F}}$ as a function of the quasi-Fermi level $E_{\mathrm{F}}$ derived from figure 5 by using the direct method [17]. An electron trap is evident at $0.55 \mathrm{eV}$.

behaviour of the trapped electron density $n_{\mathrm{t}}$ and of $\mathrm{d} n_{\mathrm{t}} / \mathrm{d} E_{\mathrm{F}}$ as a function of the quasi-Fermi level $E_{\mathrm{F}}$. Clearly, since $\mathrm{d} n_{\mathrm{t}} / \mathrm{d} E_{\mathrm{F}}$ is practically the energy distribution of trapping centers, the peak indicates a trapping center at about $0.55 \mathrm{eV}$, in a good agreement with the previous determinations.

Another typical I-V characteristics, obtained also for a n-type In-doped CdTe sample, is shown in figure 7. In this case, the trap should be located at $0.62 \mathrm{eV}$ from conduction band, and trap concentration is much higher, $N_{\mathrm{T}} \simeq 10^{12} \mathrm{~cm}^{-3}$. For completeness, still another method of analysis has been used [18] which assumes a practically gaussian energy distribution of traps, either sharp $\left(T_{\mathrm{t}}<T\right)$ or diffuse $\left(T_{\mathrm{t}}>T\right)$ depending on the value of the crytical temperature $T_{\mathrm{t}}$. By this model, $E_{\mathrm{T}}$ can be easily obtained with the expression

$$
I_{\mathrm{TFL}} \simeq \frac{e^{2} \mathrm{~d} \mu N_{\mathrm{T}} N_{\mathrm{C}}}{\varepsilon} \exp \left(-\frac{E_{\mathrm{T}}}{k T}\right)
$$

where $N_{\mathrm{C}}$ is the density of states of conduction band.

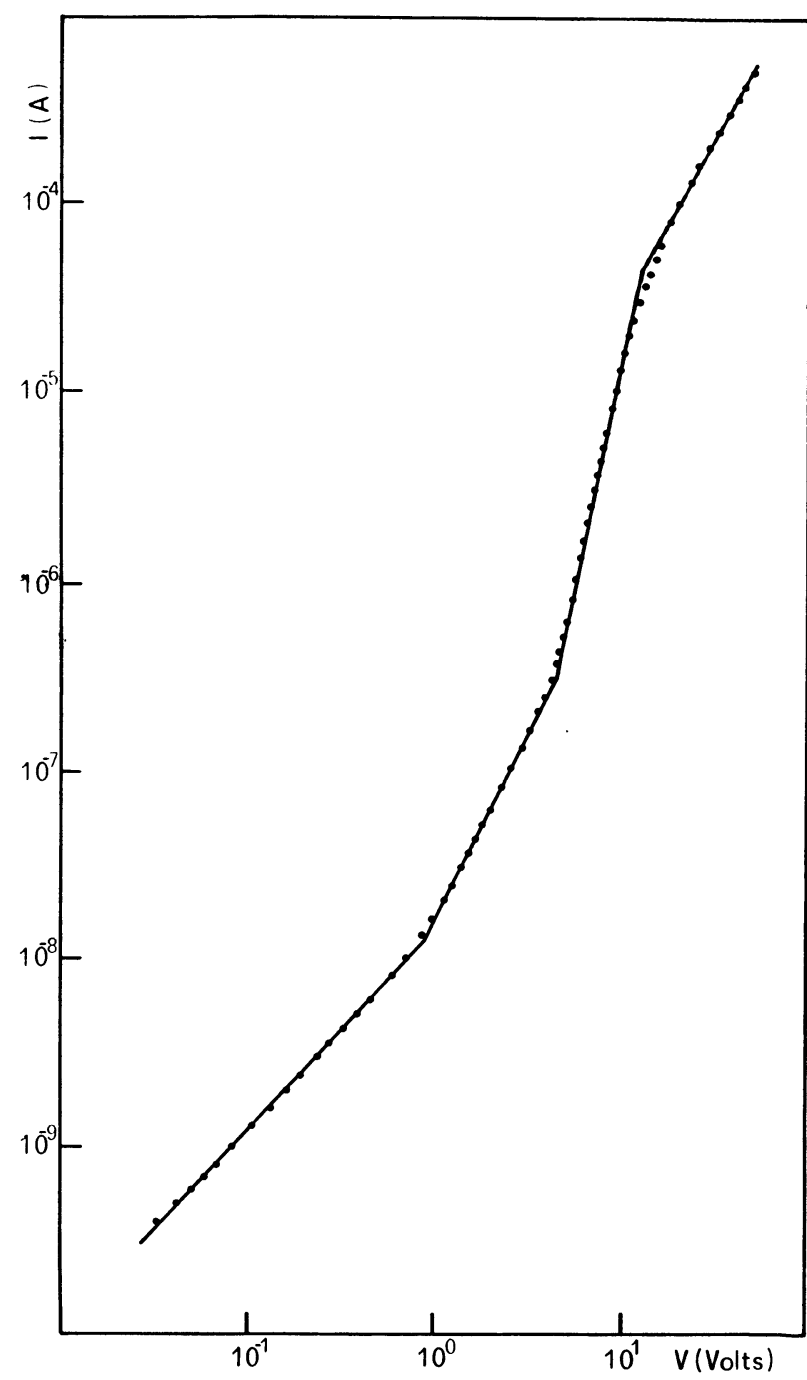

FIG. 7. - Typical I-V characteristics obtained for an In-doped sample, showing another example of an electron trapping level at $0.62 \mathrm{eV}$ from the conduction band.

A comparison among the results obtained with these different methods is shown in table III, both for electrons and hole traps.

3.3 Resistivity MEASUREMENTS. - In order to support the previous results and because Hall effect measurements in high resistivity samples were not feasible, resistivity measurements as a function of

\section{TABLE III}

Comparison between the results obtained by various methods for calculating trap depths (ET) and density $\left(N_{\mathrm{T}}\right)$ from SCLC curves

Method

Electron
Traps

Hole Traps
Manfredotti et al. [17]

$$
E_{\mathrm{T}}(\mathrm{eV}) \quad N_{\mathrm{T}}\left(\mathrm{cm}^{-3}\right)
$$$$
0.61
$$

0.52

$9 \times 10^{11}$

-

$6 \times 10^{10}$

0.38

$6 \times 10^{11}$
Mathur et al. [18]

$$
E_{\mathrm{T}}(\mathrm{eV}) \quad N_{\mathrm{T}}\left(\mathrm{cm}^{-3}\right)
$$

0.62

0.58

$9 \times 10^{11}$

$3 \times 10^{11}$

0.34

$2 \times 10^{11}$

0.39
Lampert [15]

$\begin{array}{cc}E_{\mathrm{T}}(\mathrm{eV}) & N_{\mathrm{T}}\left(\mathrm{cm}^{-3}\right) \\ - & - \\ 0.62 & 9 \times 10^{11} \\ 0.53 & 5 \times 10^{11} \\ 0.36 & 3 \times 10^{11}\end{array}$

0.36

$7 \times 10^{11}$ 
temperature were carried out in order to determine the relevant activation energies. An example is shown in figure 8 , in which activation energies $E_{\mathrm{A}}=0.34,0.047$ and $0.012 \mathrm{eV}$ are apparent (the last one might also be due to a saturation of resistivity at low temperature).

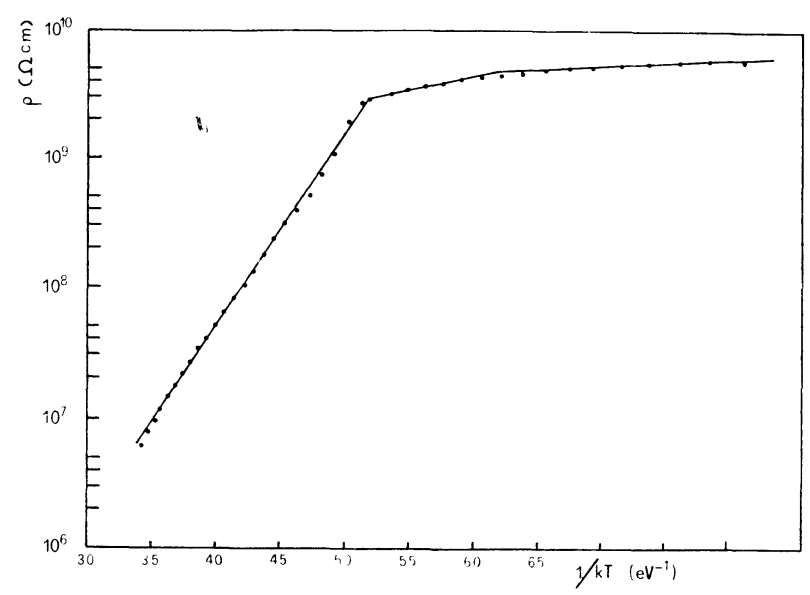

Fig. 8. - Example of a resistivity versus temperature curve for an In-doped sample. Activation energies are 0.34, 0.047 and $0.012 \mathrm{eV}$ approximately.

4. Discussion. - Table IV reports an almost complete comparison between the results obtained in the present work and by other authors. In spite of different methods used for growing CdTe, the overall agreement is quite satisfactory. We shall examine electron and hole traps separately and finally we shall compare the various methods of characterization among each other, since essentially this one was the aim of this paper.

4.1 EleCtron Centers. - Traps at $0.62 \mathrm{eV}$ and $0.53 \mathrm{eV}$ were found in materials of different resistivity and therefore it is not possible to decide if they correspond to the same trap or, in the opposite case, if the center at $0.62 \mathrm{eV}$ is present also in the lower resisti- vity material. These traps dominate the behaviour of $\mathrm{CdTe}$ at room temperature and have a relatively large capture cross-section $\left(2 \times 10^{-13} \mathrm{~cm}^{2}\right.$ for $0.62 \mathrm{eV}$ trap). It is noteworthy the agreement with ref. [24], which quotes $E_{\mathrm{T}}=0.65, N_{\mathrm{T}}=8.5 \times 10^{11}$ (see Table III) and $S_{\mathrm{T}}=4 \times 10^{-13} \mathrm{~cm}^{2}$, and which concerns pulsed SCLC measurements.

The level at about $0.35 \mathrm{eV}$ appears generally in sample of relatively low resistivity $\left(\sim 10^{5} \Omega \mathrm{cm}\right)$, but it has been detected also in higher resistivity ones $\left(10^{7} \Omega \mathrm{cm}\right)$ by TSC. It should correspond to a donor (it is clearly evident in $\rho(T)$ curves) and it should be due probably to association between native defects and impurities [21].

Finally, the level at about $0.05 \mathrm{eV}$ has been detected by many authors, it is present also in high resistivity samples, and it should also correspond to a donor (interstitial neutral Cd or substitutional neutral In) [25]. Obvious doubts can be raised for the level at $0.2 \mathrm{eV}$, which has been seen only in $\rho(T)$ curves.

4.2 Hole TRAPS. - The level at about $0.35 \mathrm{eV}$ has been evidenced by many authors and should likely correspond to charged substitutional $\mathrm{Cu}$, or $\mathrm{Ag}$ or $\mathrm{Au}$ [25], if also in highly purified crystals some of these impurities are still present. It could also correspond to a charged $\mathrm{V}_{\mathrm{Cd}} \mathrm{In}_{\mathrm{Cd}}$ complex [25]. The capture crosssection reported here (see Table II) is much smaller than previously quoted [4]. The same consideration holds for the level at $0.144 \mathrm{eV}$ [4]. The level at $0.26 \mathrm{eV}$, which should also correspond to an acceptor, has been detected only by one author [5]. It is relatively strange that the level at $0.14 \mathrm{eV}$, quoted by many authors and corresponding probably to a singly ionized $\mathrm{Cd}$ vacancy [25], is not present in our $\rho(T)$ curves, while it is present in almost all TSC curves. The level at $0.072 \mathrm{eV}$ too is often present in TSC curves, it should correspond to a donor, even if it has been quoted by only two authors [20,22], and with a satisfactory

\section{TABLE IV}

Comparison between the results obtained for trap depths $\left(E_{\mathrm{T}}\right)$ in the present work and by other authors. Energies are expressed in $\mathrm{eV}$

\begin{tabular}{|c|c|c|c|c|c|c|c|c|c|c|c|c|c|c|}
\hline & & sent Wo & & & & & & & fious & & & & & \\
\hline & $\rho(\mathrm{T})$ & SCLC & TSC & $\begin{array}{l}\text { Ref. } \\
\text { [1] }\end{array}$ & $\begin{array}{l}\text { Ref. } \\
{[2]}\end{array}$ & $\begin{array}{c}\text { Ref. } \\
\text { [3] }\end{array}$ & $\begin{array}{l}\text { Ref. } \\
\text { [4] }\end{array}$ & $\begin{array}{c}\text { Ref. } \\
{[5]}\end{array}$ & $\begin{array}{l}\text { Ref. } \\
\text { [19] }\end{array}$ & $\begin{array}{l}\text { Ref. } \\
\text { [20] }\end{array}$ & $\begin{array}{l}\text { Ref. } \\
\text { [21] }\end{array}$ & $\begin{array}{l}\text { Ref } \\
\text { [22] }\end{array}$ & $\begin{array}{l}\text { Ref. } \\
\text { [23] }\end{array}$ & $\begin{array}{l}\text { Ref. } \\
\text { [24] }\end{array}$ \\
\hline 晜 & - & - & - & - & - & - & - & - & - & - & - & - & - & - \\
\hline $\begin{array}{l}\tilde{E} \\
5\end{array}$ & - & 0.62 & - & 0.58 & & & & & 0.7 & 0.58 & 0.6 & 0.6 & & 0.65 \\
\hline ธ్ & - & 0.53 & - & & & & 0.55 & & & & & & & \\
\hline 苞 & 0.34 & 0.36 & 0.34 & & & & & & & & 0.42 & 0.38 & & \\
\hline & 0.20 & - & - & & & & & & & & & & & \\
\hline & 0.052 & - & 0.05 & & 0.048 & 0.05 & & & & & & 0.05 & 0.08 & \\
\hline & - & - & - & & & 0.02 & & & & & & & & \\
\hline & - & - & - & & & & & 0.53 & & & 0.46 & & & \\
\hline & 0.37 & 0.36 & 0.35 & & & 0.35 & 0.30 & 0.40 & 0.40 & & & & 0.30 & \\
\hline 0 & 0.26 & - & 0.25 & & & & & 0.25 & & & & & & \\
\hline 0 & - & 一 & 0.144 & & & & 0.13 & 0.18 & & & & & 0.15 & \\
\hline & 0.076 & - & 0.072 & & & & & & 0.05 & & & 0.09 & & \\
\hline & 0.025 & - & - & & & & & & & 0.02 & & & & \\
\hline
\end{tabular}


agreement with respect to $S_{\mathrm{T}}$ [20]. It has been attributed to a singly charged complex containing a $\mathrm{Cd}$ vacancy [19].

4.3 COMPARISON BETWEEN TSC AND SCLC METHODS. - At a first sight, TSC and SCLC methods seem to be quite complementary in nature, since while the former one is more indicated for shallow traps, the latter one can detect more easily deep traps, if carried out at room temperature (see Table IV). The last one is clearly the most important advantage of SCLC technique, since it gives detailed informations concerning trapping levels lying just above the Fermi level at room temperature, and which should clearly more heavily affect the performances of $\mathrm{CdTe}$ as nuclear detector. Another advantage, already emphasized, is that this technique is very sensitive to low concentrations of traps (see Table III) or, better, it is even easier to apply when trap densities are low, since $V_{\mathrm{TFL}}$ is lower in these cases (see eq. (1)). Finally, SCLC in steady state conditions is an easy, inexpensive technique, which gives practically immediate results, with no problems concerning data analysis.

The drawbacks of SCLC lie in the fact that identification of injected carriers is not provided (but it can be supplied by pulsed SCLC) and that the realization of injecting contacts may present some difficulties.

As far as TSC technique is concerned, problems were encountered in low resistivity samples, because of the high dark currents, and some memory effects, which presented the use of the thermal cleaning techniques. However, in these cases, the reconstruction method proposed by Khare and Ranade [8] worked satisfactorily. Superposing or interfering peaks are clearly a problem for TSC method : as an example, they may lead to incorrect results for the initial rise analysis [6], if a small peak lies in the low temperature tail of an higher temperature one. Moreover, if one applies other methods, there is the problem of deciding the kinetics order. In this respect, it seems that the method of analysis proposed by Chen $[9,10]$ is to be preferred, since it is kinetics-independent.

\section{References}

[1] Zanio, K. R., Akutagawa, W. M. ad Kikuchi, R., J. Appl. Phys. 39 (1968) 2818.

[2] Canali, C., Nava, F., Ottaviani, G. and Zanio, K., Phys. Stat. Sol. (a) 28 (1975) 581.

[3] Bell, R. O., Wald, F. V. and Goldner, R. B., IEEE Trans. Nucl. Sci. NS-22 (1975) 241.

[4] Schrager, C., Muller, J C., Stuck, R. and Siffert, P., Phys. Stat. Sol. (a) 31 (1975) 247.

[5] Martin, G. M., Fabre, E., Fogarassy, E., Belin, C. and NGo-Tich-PHUOC, IEEE Trans. Nucl. Sci. (NSS S. Francisco, 19-21 nov. 1975).

[6] Garlick, G. F. J. and Gibson, A. F., Proc. Phys. Soc. 81 (1948) 141.

[7] HaAke, C. H., J. Opt. Soc. America 47 (1957) 649.

[8] Khare, R. P. and Ranade, J. D., Phys. Stat. Sol. (a) 32 (1975) 221.

[9] Chen, R., J. Appl. Phys. 40 (1969) 570.

[10] CHEN, R., J. Electrochem Soc. 116 (1969) 1254.

[11] Bube, R. H., Dussel, G. A., Ching-TaO-Ho and MiLLER, L. D., J. Appl. Phys. 37 (1966) 21.

[12] LushCHIK, C. B., Dokl. Akad. Nauk. S. S. S. R. 101 (1955) 641.

[13] Keating, P. N., Proc. Phys. Soc. 78 (1961) 1408.

[14] Grossweiner, L. I., J. Appl. Phys. 24 (1953) 1306.
[15] Lampert, M. A., Phys. Rev. 103 (1956) 1648.

[16] MotT, N. F. and Gurney, R. W., Electronic Processes in Ionic Crystals (Oxford Univ. Press), Oxford 1940.

[17] Manfredotti, C. De Blasi C., Galassini, S., Micocci, G., Ruggiero, L. and Tepore, A., Phys. Stat. Sol. (a), 36 (1976) 569.

[18] Mathur, V. K. and Dahija, R. P., Solid State Electron. 17 (1974) 61.

[19] Vul, B. M., Vavilov, V. S., Ivanov, I. S., Stopachinsky, B. and Chapnin, V. A., Proc. Int. Symp. CdTe, Strasbourg 29-30 June 1971, p. XI-I.

[20] Marfaing, Y., Lascaray, J. and Triboulet, R., Metal Semicond. Conf., Manchester 1974, London 1974 (p. 22).

[21] CaIllot, M., Ref. [19], page XIII-1.

[22] Cumpelik, R., Kagerova, J. and Klier, E., Czech. J. Phys. B 19 (1969) 1003.

[23] Agrinskaya, N. V., Arkadeva, E. N., Matveev, O. A. and Rud, Y. V., Sov. Phys. Semicond. 2 (1969) 776.

[24] Canali, C., Nigolet M. A. and Mayer, J. W., Solid State Electron. 18 (1975) 871.

[25] KRöGER, F. A., The chemistry of imperfect crystals (NorthHolland, Amsterdam) 1964, p. 672. 